\title{
MOOC DE LITERACIA MIDIÁTICA E INFORMACIONAL NO CONTEXTO DA DESORDEM DA INFORMAÇÃO
}

\section{Media and Informational Literacy MOOC in the context of Informational Disorder}

\author{
Lílian Tropiano ${ }^{1}$
}

\begin{abstract}
Resumo: O compartilhamento de conteúdo falso é potencializado pelas redes sociais, manifestando-se como ameaça às democracias, visto que ganha rápida adesão e transforma a opinião pública. Essa ação faz parte do fenômeno chamado de desordem da informação em rede. A literacia midiática e informacional se torna, portanto, uma competência chave para o cidadão na era digital, que vive em uma sociedade em que as mídias estão em convergência e têm poder de alcance amplificado na internet. $\mathrm{O}$ artigo objetiva: a) verificar se há oferta de MOOCs que promovam a literacia midiática e informacional; b) compreender as dimensões tecnológica, operacional, temática e pedagógica desses MOOCs. Como resultados foram encontrados sete MOOCs que abordam as habilidades da competência em questão, dos quais foram selecionados dois para uma descrição analítica a fim de reconhecer suas potencialidades como recurso de enfrentamento aos fenômenos da desordem da informação.
\end{abstract}

Palavras-chave: MOOC. Literacia midiática e informacional. Desordem da informação. TIC. Cidadania ativa.

\begin{abstract}
The sharing of false content is enhanced by social networks, manifesting itself as a threat to democracies, since it quickly gains adherence and transforms public opinion. This action is part of the phenomenon called networked information disorder. Therefore, media and information literacy become a key competence for the citizen in the digital age, who lives in a society where media are in convergence and have amplified reaching power on the Internet. The article aims: a) to verify if there are MOOCs that promote media and information literacy; b) to understand the technological, operational, thematic and pedagogical dimensions of these MOOCs. As results we find seven courses that address the skills of the competence in question, of which two were selected for an analytical description to recognize their potential as a resource for facing the phenomena of information disorder.
\end{abstract}

Keywords: MOOC. Media and information literacy. Information disorder. ICT. Active citizenship.

\footnotetext{
${ }^{1}$ Professora I da Prefeitura de Nova Iguaçu (RJ), Mestre em Mídia e Cotidiano (PPGMClUFF) e Doutoranda em Educação - Especialidade Tecnologia da Informação e Comunicação na Educação - pela Universidade de Lisboa. https://orcid.org/0000-0003-1908-7903 Contato: lilianwilsontropiano@edu.ulisboa.pt
} 


\section{Introdução}

A literacia midiática e de informação é apontada por governos, organizações e especialistas como uma competência que deve ser promovida a fim de empoderar os cidadãos para o enfrentamento do fluxo informacional que ocasiona a desordem da informação, como reforçado pela Declaração de Seul (UNESCO, 2020). Assim, no mundo conectado pela internet as pessoas não são apenas consumidoras de informação, eles passam a atuar ativamente sobre elas quando as compartilham ou produzem conteúdos para as redes.

Cada vez mais o MOOC (Massive Online Open Course, no português Curso Massivo Aberto e Online) é um recurso utilizado por empresas, universidades e instituições para a atualização de competências sobre vários campos do conhecimento. $\mathrm{Na}$ concepção do empoderamento, o MOOC é composto por recursos pedagógicos que irão fazer a mediação do processo educativo em que se estimule o pensamento crítico que por sua vez geram muitas outras possibilidades.

Nesse artigo são tecidas reflexões sobre o MOOC enquanto uma ferramenta que possibilita a aprendizagem ao longo da vida, em especial da literacia midiática e informacional. No contexto específico da desordem da informação e das constantes mudanças na sociedade da informação é importante a compreensão das formas de atualização do conhecimento sobre mídias para promover a cidadania ativa no ambiente digital. Sendo assim, pretende-se lançar luz à problemática do fenômeno social (a desordem da informação) e em uma estratégia educacional (MOOC) que possa desenvolver habilidades que auxiliem os cidadãos em geral a enfrentarem tal questão. $O$ intuito aqui é identificar se há a ocorrência de MOOC de literacia midiática e informacional disponíveis e se tais MOOCs podem ser um recurso educacional ao enfrentamento dos fenômenos da desordem da informação.

O percurso metodológico deste artigo é composto por: reflexão sobre o cenário da desordem da informação, compreensão da literacia midiática e informacional como promotora de cidadania, compreensão das tipologias dos MOOC e pesquisa de campo (critério da seleção dos MOOC e descrição analítica). A pesquisa de campo foi desenvolvida com objetivo de identificar se havia de fato uma oferta de MOOC que abordasse a temática da literacia midiática e informacional. Para este artigo, foram selecionados dois dos MOOCs encontrados na pesquisa de campo, e que são oferecidos por uma mesma instituição, mas que apresentam diferenças em sua operacionalidade.

Na primeira parte do artigo, busca-se traçar o cenário sociopolítico da desordem da informação no Brasil a título de possibilitar a compreensão desse contexto específico e o acionamento de políticas específicas ao seu enfrentamento. Em seguida, no tópico 3, são acionadas algumas reflexões da literacia midiática e informacional, por ser um recurso proposto por diversas entidades sociais para o enfrentamento da desinformação, sobretudo no cenário de rápidas mudanças no campo de tecnologia da comunicação e informação (TIC). Assim, são abordados os aspectos gerais dos MOOCs e suas tipologias para depois compreender em específico a dinâmica de dois MOOCs promotores da literacia midiática e informacional.

Este artigo é parte do projeto em curso intitulado "Características do MOOC promotor de literacia midiática e informacional no contexto da desordem da informação em rede", que objetiva criar reflexões sobre os MOOCs que promovem literacia midiática e informacional 
no contexto da desordem da informação sob o viés da inovação e dos recursos tecnológicos para a aprendizagem.

\section{Contextualizando a desordem da informação a partir do Brasil}

O relatório do Reuters Institute for the Study of Journalism de 2019 aponta como as notícias estão sendo consumidas em diferentes países, entre eles no Brasil. O mesmo relatório de 2019 traz como pano de fundo o cenário político do populismo crescente, das instabilidades políticas e econômicas, bem como a preocupação com os impactos das grandes empresas de comunicação na sociedade. Dentro disso, pontua a polarização política que encorajou a difusão online das pautas partidárias que junto do clickbait e das diversas formas de desinformação geraram uma desconfiança por parte da sociedade em relação à mídia tradicional (NEWMAN, 2019, p. 10).

Outro dado apontado pelos Estudos de Jornalismo da Reuters (NEWMAN et al, 2019) que auxilia a compreensão do fenômeno da desinformação em rede no Brasil é o crescente uso dos aplicativos de mensagens para ter acesso às informações, como por exemplo o WhatsApp. Em relação ao Brasil, 53\% dos participantes da pesquisa usam o aplicativo de mensagem como meio para consumir informação, consequentemente, o acesso por mobile para acessar notícias também aumentou.

Já o relatório de 2020 do Reuters Institute (NEWMAN et al, 2020) tem como pano de fundo a pandemia do Coronavírus sem precedentes na história contemporânea da humanidade, cujas consequências sociais e políticas ainda não podem ser entendidas por completo. Entretanto, nesse período ficou evidenciada a necessidade do trabalho de campo do Jornalismo em termos de informar e educar a população para os protocolos de saúde a serem adotados, sendo a desinformação em rede um dos principais desafios para implementação de ações de segurança também em relação à saúde pública.

Tendo em vista o relato da Reuters, em 2020, mais da metade do total de participantes se veem preocupados em relação à confiabilidade da informação que consomem. $O$ estudo ainda aponta que no Sul Global essa preocupação aumenta (Brasil 84\%, Quênia 76\% e África do Sul 72\%), sendo o Brasil o país que apresenta o maior índice da pesquisa. As fontes online de informação são as mais utilizadas pelos brasileiros, incluindo as redes sociais - as mais utilizadas são, respectivamente, Facebook, WhatsApp e YouTube.

Essa preocupação dos internautas é reveladora de inúmeras questões. Embora o campo investigativo na área de Literacia Midiática no Brasil tenha estudos de relevância, há em relação às políticas públicas específicas para a questão uma imensa defasagem. Desta forma, observa-se a falta de comprometimento de órgãos governamentais e, principalmente, dos conglomerados de mídia em desempenhar esforços coordenados.

Desde 2016, vêm sendo discutidos os impactos da difusão de notícias falsas ou incorretas dentro do cenário da comunicação em rede. Essas discussões inicialmente centraram-se na noção de fake news, a palavra do ano escolhida pelo dicionário Oxford em 2017. O advento das redes sociais é um fator potencializador da disseminação em larga escala de desinformação (BULGER; DAVISON, 2018), principalmente quando o sistema de algoritmo produz uma indução de conteúdos sugeridos, gerando as bolhas sociais e 
consequentemente as polarizações de ideias, visto que se produz uma espécie de câmara de ecos de realidades. Segundo Lopes (2019), três fatores propulsionam os conteúdos falsos a ganharem larga difusão nas redes: a estrutura do conteúdo, a apresentação de novos atores e a falta de competência de quem lê/ouve/vê o conteúdo.

A desinformação é uma problemática antiga, mas que ganha nova proporção na era da informação em rede (IRETON; POSENTTI, 2018; UNESCO, 2013). No campo da Comunicação Social já se compreende que o termo fake news é generalista e apresenta incongruências devido à complexidade do fenômeno e, também, por ter sido apropriado pelo senso comum (WARDLE, 2019). A desordem da informação é a terminologia mais adequada para o fenômeno, pois engloba a natureza e a escala da problemática, ou seja, aborda a questão por meio de um ecossistema. Portanto, a desordem da informação engloba: a) Desinformação (Dis-information) - a difusão de informação falsa para causar um dano, ou seja, um ato propositado; b) Informações incorretas (Mis-information) - a difusão da informação falsa sem a intenção de causar dano, um ato não propositado; c) Má informação (Mal-information) - uma informação verdadeira (genuína) que é compartilhada para causar dano, sendo o teor desta informação muitas vezes de cunho privado (seja jurídico, ou político) com nítida intenção de causar dano (WARDLE, 2019).

Recentemente, o fluxo de informações gerado na pandemia da Covid-19 foi chamado de infodemia (ZAROCOSTAS, 2020), sendo este um exemplo de como funciona a desordem da informação. As inúmeras informações veiculadas na internet nem sempre são baseadas em padrões oficiais que são regidos por estudos científicos, assim, a disseminação dessas informações incorretas tem se mostrado um atentado direto à saúde pública em diversos países, principalmente naqueles menos eficientes na resposta à doença. Nesse cenário, é urgente a reflexão sobre formas de uso dos recursos digitais online que empoderem os cidadãos para lidar com os fenômenos da desordem da informação.

A Comissão Parlamentar Mista de Inquérito do Congresso Nacional (CPMI) das Fake News está investigando os ataques cibernéticos que atentam contra a democracia e o debate público, a utilização de perfis falsos para influenciar os resultados das eleições 2018; a prática de ciberbullying sobre os usuários mais vulneráveis da rede de computadores, bem como sobre agentes públicos; e o aliciamento e orientação de crianças para o cometimento de crimes de ódio e suicídio. Essa comissão revelou o cenário alarmante da desinformação em que se encontra o Brasil.

Em 2019, algumas medidas já foram tomadas pela Comissão Parlamentar Mista de Inquérito (CPMI), como bloqueio de perfis falsos e ações judiciais contra as empresas envolvidas em disparos de notícias falsas em massa. A CPMI das Fakes News também impulsionou o parlamento a propor um projeto de lei (PL 2630/20) para estabelecer normas, diretrizes e mecanismos de transparência para provedores de redes sociais e de serviço de mensagem privada. Nesse projeto de lei, o grupo de trabalho ressaltou a importância da inclusão de forma mais específica da educação midiática. A Comissão cita a Lei do Marco Civil na Internet (Lei $\mathrm{N}^{\mathrm{o}} 12.965$, de 23 de abril de 2014), a qual estabelece princípios, garantias, direitos e deveres para o uso da Internet no Brasil, mas que se encontra defasada para o cenário da desordem da informação. Também no que se refere à educação, não focaliza de forma específica as ações para a promoção da educação midiática.

As iniciativas na área da educação midiática no Brasil ainda são tímidas, principalmente em um cenário de trabalho conjunto das diferentes instâncias sociais. No 
campo curricular da educação formal no Brasil, a BNCC (Base Nacional Curricular Comum) apresenta um salto em nível curricular com maior focalização na educação midiática, entretanto a inclusão de habilidades de competência midiática no currículo, em 2017, ainda está longe de ser desenvolvida na prática. Outra questão a se pensar é a própria regulamentação da internet, bem como o trabalho mais incisivo dos conglomerados de mídia no país e sua responsabilidade social na promoção da educação midiática, tendo-se um maior alinhamento entre o campo investigativo e o da prática social.

\title{
3 Literacia midiática e informacional para promover cidadania na internet
}

Segundo Borges, Sigiliano e Guida (2021), os estudos sobre literacia midiática e, consequentemente, o seu conceito é pautado pela pluralidade de áreas e suas intercessões. Assim, a literacia midiática é abordada por uma série de nomenclaturas correlatas: como letramento midiático, alfabetização midiática, educação midiática e educação para as mídias. No presente artigo, é utilizado o termo literacia midiática para se referir ao conjunto de habilidades que são mobilizadas para a compreensão dos conteúdos veiculados pelas mídias, englobando também a literacia informacional. A NAMLE (U. S. Nacional Association for Media Literacy Education) define a literacia midiática como "a habilidade de acessar, analisar, avaliar, criar e fazer uso ativo de todas as formas de comunicação" (BULGER; DAVISON, 2018, p. 4). Hobbs (2010) argumenta que estas cinco habilidades que compõem a literacia midiática (acessar, analisar, avaliar, criar e fazer uso ativo) são operacionalizadas juntas em um processo que gera o empoderamento, pois fornece mecanismos para uma aprendizagem ativa ao longo da vida das pessoas.

Dentro da concepção freiriana (FREIRE, 1994, 2005, 2015), o empoderamento passa pelo desenvolvimento dialógico de ser humano, em que os envolvidos aprendem durante a experiência educativa com os seus pares, mediadores e com a realidade circundante. Assim, a educação é uma prática libertadora. Segundo Freire e Shor (1986, p. 135):

\begin{abstract}
Mesmo quando você se sente, individualmente, mais livre, se esse sentimento não é um sentimento social, se você não é capaz de usar sua liberdade recente para ajudar os outros a se libertarem através da transformação da sociedade, então você só está exercitando uma atitude individualista no sentido de empowerment da liberdade. (FREIRE; SHOR, 1986, p. 135).
\end{abstract}

Desta forma, empoderar não é conferir a alguém um poder: é uma troca de instrumentalização mútua. O professor enquanto mediador do processo educativo dispõe de uma gama de alternativas que estimulam o pensamento crítico, que por sua vez irá abrir muitas outras possibilidades. Já na aprendizagem autorregulada (comum no EAD), a mediação se dá através da articulação feita pelo estudante em sua experiência de aprendizagem. Portanto, o conjunto de habilidades que conformam a literacia midiática (acessar, analisar, avaliar, criar e fazer uso ativo do conteúdo midiático) são instrumentos de empoderamento social, ou seja, atuam na construção da cidadania ativa. Essa ação de "empoderar-se" é um processo de tomada de consciência por meio do pensamento crítico, por meio da educação midiática que gera uma consciência cidadã. Assim, é uma prática que constrói autonomia nas mulheres e nos homens, tornando-os capazes de transformarem a si e à sociedade. 
A literacia informacional dá ênfase ao acesso, avaliação e uso ético das informações, enquanto a literacia midiática prioriza a compreensão e avaliação das funções da mídia em prol de um engajamento consciente às mídias. A UNESCO (2013) une a literacia midiática e a literacia informacional em um único domínio: literacia midiática e informacional. $\mathrm{Na}$ interseção de ambas as literacias, é possível acioná-las em conjunto, principalmente entendendo que informar é uma das funções essenciais da mídia. Dessa forma, adota-se neste estudo tal concepção da literacia midiática.

A literacia midiática e informacional (LMI) enquanto estratégia para combater os impactos sociais da desordem da informação em rede é defendida por organizações e estudiosos (BULGER;DAVISON, 2018; UNESCO, 2020). Também, consideram que o desenvolvimento dessa literacia não se deve limitar ao ambiente escolar formal (através da inserção nos currículos), devendo ser promovido por diversas áreas e setores, inclusive pelo meio empresarial, visto que ampla parte da sociedade é consumidora (e, potencialmente, produtora) de conteúdo em rede (BULGER; DAVISON, 2018; LOPES, 2019).

Devaux et al. (2019) pontua que a promoção da literacia midiática dos consumidores é uma ação importante para combater a vulnerabilidade à desinformação, contudo, também são importantes pesquisas baseadas no comportamento das pessoas em relação às mídias no que concerne à tomada de consciência da ação individual sobre as mídias e das influências delas sobre as pessoas. Bulger e Davison (2018) apontam que, para além da ação educativa, faz-se necessária a participação governamental em legislar e fiscalizar práticas criminosas nas redes, bem como o desenvolvimento por parte dos conglomerados de mídia de ações para o tratamento ético da informação e do entretenimento. Em relação ao tratamento da informação no Brasil, há um movimento crescente da articulação do campo jornalístico em ações de fact-checking como: a agência Lupa, UOL Confere, Projeto Comprova, Fato ou Fake, dentre outros.

A educação no século XXI aborda as questões sociais relacionadas ao trânsito de pessoas e informações no mundo globalizado, cujo sentimento de cidadania vem de ser atuante no mundo. Dessa forma, a noção de cidadão global (UNESCO, 2015) aciona ações que geram impacto em nível local e global. Tais ações devem ser pautadas por uma lógica ecológica. Assim, num mundo globalizado conectado pelos usos em rede da Internet, a literacia midiática e informacional não pode mais ser entendida sem estar englobada às competências digitais e aos impactos socioambientais. Portanto, ressalta-se que este artigo também compreende a literacia midiática e informacional dentro do contexto das competências digitais do cidadão do século XXI propostas por Carretero, Vouriki e Punie (2017).

É necessária a compreensão global da desordem da informação, ou seja, entender o ecossistema do fenômeno e os processos que levam à projeção da desinformação, por isso a importância dos estudos dessa temática no âmbito da Comunicação Social, das Tecnologias da Informação e da Educação. Com a compreensão da desordem da informação enquanto um fenômeno que engloba diversas atividades que se utilizam dos processos comunicacionais midiáticos, é possível reconhecer que as práticas de promoção de literacia midiática e informacional são ferramentas imprescindíveis no enfrentamento dos processos de desinformação no que concerne ao empoderamento do cidadão, de maneira que este revise as suas práticas comunicacionais. 


\section{MOOC: Tipologias e problematizações}

A globalização em curso no último milênio se apresenta cada vez mais potente dentro das conexões digitais. São lançados constantemente desafios às formas tradicionais de se viver em sociedade. Na aprendizagem, a exigência social se foca em direcionar não mais nos conteúdos recebidos (logo, transmitidos), mas sim nos resultados do processo de aprendizagem: as aprendizagens por competência. Essa mudança é proveniente das constantes transformações, principalmente tecnológicas, que impulsionam novas sociabilidades (STRICKE, 2018).

Toda a formação por si já é defasada quando forma no e para o presente. A aprendizagem se volta sempre ao futuro, forma-se para o amanhã, portanto, a ação educativa voltada ao aprender a aprender é um movimento para a reflexão constante da aprendizagem frente às inovações tecnológicas. Já não cabe a proposição de uma educação para o século XXI, pois esse já é uma realidade em vivência. A educação no século XXI lida com inúmeras transformações em curso que exigem dos cidadãos, para além da postura pró-ativa e multifuncional, a capacidade de aprender e reaprender diversas coisas ao longo da vida (APPLE, 2017).

Carmo e Carmo (2018) trazem um olhar sociológico em relação às mudanças nos processos educacionais, apontando que, na conjuntura da revolução tecnológica, a educação de transmissão se revela insuficiente. Por conseguinte, as mudanças do cenário social são propulsoras para o aprimoramento de processos da educação ao longo da vida que sejam capazes de "adaptar a novas situações e a resolver problemas desconhecidos das gerações anteriores" (CARMO; CARMO, 2018, p. 37). Nessa conjuntura, os autores apontam para o MOOC como um recurso educacional contemporâneo para a educação de cidadania, principalmente por aprofundar a vivência com o mundo digital, e para se trabalhar a perspectiva de aprendizado ao longo da vida no contexto da educação não formal e continuada.

O MOOC é uma modalidade de ensino a distância relativamente nova que se estrutura como um ambiente virtual de aprendizagem (AVA). O aprendizado online possibilita flexibilidade, visto que é acessível a todos em qualquer momento e espaço desde que tenha conexão com a internet. Por ser uma ferramenta educacional massiva e aberta, o MOOC opera como um recurso eficiente para abordar tópicos de relevância social e que sofrem constantes atualizações devido aos avanços tecnológicos, como a literacia midiática (GREENE; OSWALD; POMERANTZ, 2015; MISSOPOULOS; ARGYROPOULOU; TZAVARA, 2018).

Existe uma variedade de tipos de MOOC. Os chamados cMOOC são baseados no estímulo de interações entre os seus participantes, dessa forma se estimula a troca de ideias, podendo até se criar comunidades de aprendizagem conforme o avanço da interatividade entre os participantes. A letra $\mathrm{C}$ refere-se ao conectivismo e tem origem com o primeiro MOOC que foi oferecido em 2008 por George Siemens (Universidade de Athabasca) e Stephen Downes (Conselho Nacional de Pesquisa do Canadá). O MOOC proposto pelos pesquisadores tinha o objetivo de abordar o assunto "Connectivism and Connected Knowledge" por meio do estímulo da conexão entre os participantes, para tanto, foram combinados o uso de blogs, da plataforma moodle e de redes sociais. Já o xMOOC, uma segunda geração, é o curso que se baseia no modelo tradicional de ensino, combinando vídeos e textos que servem como suporte 
para o estudante responder aos questionários e testes de avaliação de conhecimento. Também, o xMOOC apresenta os componentes curriculares estruturados de forma engendrada e numa crescente de complexidade temática. As primeiras plataformas que abrigaram este tipo de curso foram a Coursera, Udacity e edX (WAKS, 2016).

O cMOOC e xMOOC são os tipos de MOOC que existem em relação a sua função pedagógica e que vêm sendo amplamente utilizados (YOUSEF et al, 2014; ALDAHMANI, 2020). Há outros tipos de MOOC catalogados por estudiosos, como o estudo de Ribeiro e Catapan (2018) que lista 22 tipos de MOOCs. Percebe-se que estas demais categorias de MOOC que vêm sendo catalogadas partem do cMOOC e do XMOOC como essência, sendo dessa forma uma subcategoria.

Stracke et al (2019) aponta que a diferença entre os dois tipos principais de MOOC está na ênfase pedagógica: enquanto o cMOOC enfatiza a criação de redes colaborativas entre seus participantes, que compartilham recursos e informações, o xMOOC enfatiza o conteúdo passado de forma tradicional para uma grande audiência, sendo dessa forma o professor (equipe de professores) o principal condutor das atividades.

Em relação à taxa de abandono elevada, que é a crítica mais recorrente após a explosão do MOOC enquanto um fenômeno educacional, Stracke (2017) propõe outra forma de compreender a qualidade dos MOOCs. O estudioso recomenda a focalização em outros critérios pedagógicos como o cumprimento de objetivos e intenções individuais dos alunos que completam o curso. O olhar para os objetivos na ótica do realizador do curso, mas também na ótica do aluno, está relacionada ao entendimento do MOOC enquanto um produto e também enquanto um processo de aprendizagem. Nesse sentido, Stracker (2017) aponta o MOOC como um mecanismo educacional que estimula competências de autorregulação da aprendizagem, capacidades cada vez mais necessárias na modalidade e-learning. Assim, ao invés de avaliar a qualidade do MOOC pela quantidade de alunos que concluíram o curso, avalia-se pela apreciação e desempenho dos estudantes concluintes.

Enquanto um recurso educacional aberto, o MOOC se apresenta como um conteúdo disponível ao acesso dos usuários da internet em que é possível o contato com os materiais que o compõem sem a necessidade do estudante ser um cursista. Já enquanto uma oferta de ensino, relaciona-se ao fazer do curso em si. Portanto, o MOOC, enquanto um produto, seria um tipo especial de recurso educacional aberto (REA), e o MOOC, enquanto processolexperiência, seria um tipo especial de aprendizagem aprimorada pela tecnologia (STRICKE, 2017).

\section{O MOOC de literacia midiática e informacional}

Entre os meses de janeiro e abril de 2020, catalogou-se a existência de sete MOOCs que abordam algum aspecto da literacia midiática, por meio do buscador MOOClist. Na plataforma FutureLearn, foram encontrados três cursos, e na Coursera, quatro.

Encontrou-se, também, um MOOC sobre literacia midiática na página da União Europeia específico para a formação continuada de professores. O projeto Sml4change (Social Media Literacy For Change) recorreu ao formato MOOC enquanto recurso para a promoção da literacia midiática no contexto da formação de professores. O projeto foi coordenado pela 
European Schoolnet, seguindo a agenda de Cidadania Digital, com o apoio de uma rede de 34 Ministérios da Educação, incluindo o de Portugal. Este projeto foi cofinanciado pela União Europeia, sob o programa piloto Media Literacy for All.

Continuando a investigação a fim de reconhecer a disponibilidade de oferta de MOOC sobre literacia midiática, em fevereiro de 2021, encontrou-se no portal da UNESCO, na seção de literacia midiática e informacional, uma subseção destinada aos MOOC da MIL (Media and Informacional Literacy, em português Literacia Midiática e Informacional). A Unesco lista 4 MOOCs, sendo três adaptações. As três adaptações são oferecidas em espanhol, português e inglês (este último destinado à realidade da Etiópia).

Tabela. 1 - Resultado do Estado da Arte: oferta de MOOC MIL

\begin{tabular}{|c|c|c|}
\hline \multicolumn{3}{|c|}{$\begin{array}{l}\text { Oferta de MOOC promotores de literacia midiática e informacional } \\
\text { (Resultado do Estado da Arte) }\end{array}$} \\
\hline Título do MOOC & Plataforma & Objetivo \\
\hline $\begin{array}{l}\text { The Power of Social Media } \\
\text { Duração: } 2 \text { semanas } \backslash 3 \mathrm{~h}\end{array}$ & $\begin{array}{l}\text { FutureLearn } \\
\text { Instituição: Universidade de } \\
\text { Southampton }\end{array}$ & $\begin{array}{l}\text { Aprender como fazer um melhor uso } \\
\text { de suas redes sociais. }\end{array}$ \\
\hline $\begin{array}{l}\text { Understanding Media: } \\
\text { Introduction to Media Literacy } \\
\text { and Representation } \\
\text { Duração: } 2 \text { semanas } \backslash 3 \mathrm{~h}\end{array}$ & $\begin{array}{c}\text { FutureLearn } \\
\text { Instituição: Universidade de } \\
\text { Newcastle (Austrália). }\end{array}$ & $\begin{array}{l}\text { Identificar a questão da representação } \\
\text { em relação às mídias. }\end{array}$ \\
\hline $\begin{array}{c}\text { Making Sense of Data in the } \\
\text { Media } \\
\text { Duração: } 2 \text { semanas } \backslash 3 \mathrm{~h}\end{array}$ & $\begin{array}{l}\text { FutureLearn } \\
\text { Instituição: Universidade de } \\
\text { Sheffield. }\end{array}$ & $\begin{array}{c}\text { Compreender sobre as estatísticas dos } \\
\text { dados econômicos e sociais presentes } \\
\text { na mídia. }\end{array}$ \\
\hline $\begin{array}{l}\text { English for Media Literacy } \\
\text { Duração: } 40 \mathrm{~h}\end{array}$ & $\begin{array}{c}\text { Coursera } \\
\text { Instituição: Universidade da } \\
\text { Pensilvânia }\end{array}$ & $\begin{array}{c}\text { Aprender como a mídia americana } \\
\text { funciona. Destinado aos não nativos do } \\
\text { inglês. }\end{array}$ \\
\hline $\begin{array}{l}\text { Making Sense of the News: } \\
\text { News Literacy Lessons for } \\
\text { Digital Citizens } \\
\text { Duração: } 11 \mathrm{~h}\end{array}$ & $\begin{array}{c}\text { Coursera } \\
\text { Instituição: Parceria da } \\
\text { Universidade de Hong Kong } \\
\text { com a Universidade Estadual } \\
\text { de Nova York }\end{array}$ & $\begin{array}{c}\text { Desenvolver pensamento crítico para } \\
\text { identificar informações confiáveis nos } \\
\text { novos suportes de mídia. }\end{array}$ \\
\hline $\begin{array}{c}\text { e-Learning Ecologies: } \\
\text { Innovative Approaches to } \\
\text { Teaching and Learning for the } \\
\text { Digital Age } \\
\text { Duração: } 27 \mathrm{~h}\end{array}$ & $\begin{array}{l}\text { Coursera } \\
\text { Universidade de Illinois }\end{array}$ & $\begin{array}{c}\text { Compreender como as tecnologias } \\
\text { podem trazer inovações para a } \\
\text { educação. }\end{array}$ \\
\hline $\begin{array}{c}\text { Social Media Literacy for } \\
\text { Change } \\
\text { Duração: } 6 \text { semanas e meia } \backslash 5 \\
\mathrm{~h}\end{array}$ & $\begin{array}{l}\text { School Net Academy } \\
\text { Instituição: União Europeia }\end{array}$ & $\begin{array}{l}\text { Compreender o que é literacia } \\
\text { midiática, suas estratégias, como } \\
\text { implementar suas estratégias e como } \\
\text { avaliar o impacto das estratégias. }\end{array}$ \\
\hline $\begin{array}{l}\text { Media and Information and } \\
\text { Intercultural Dialogue (MILID) } \\
\text { Duração: } 10 \text { Semanas }\end{array}$ & $\begin{array}{c}\text { UNESCO } \\
\text { Instituição: 1a Versão } \\
\text { Universidade de Athabasca } \\
\text { (Canadá). Demais versões: } \\
\text { UNICAMP (Brasil), } \\
\text { Universidade Autônoma do } \\
\text { Estado de Morelos (Espanha), } \\
\text { União Africana e Pan-africana } \\
\text { com E-University. }\end{array}$ & $\begin{array}{c}\text { Desenvolver as habilidades de literacia } \\
\text { midiática e informacional no contexto } \\
\text { de diálogo intercultural. }\end{array}$ \\
\hline
\end{tabular}

Fonte: Elaborado pela autora (2021). 
Todos os MOOC encontrados são da tipologia xMOOC e são vinculados a pelo menos uma universidade. Waks (2016) aponta para essa característica dos MOOC quando fala sobre a incorporação dessa modalidade de ensino como forma de reduzir os cursos universitários para os alunos e a instituição. Assim, alguns desses cursos, mesmo sendo ofertados não só para o público interno das universidades, servem como crédito de alguns cursos quando feitos pelos alunos da universidade que os oferecem. Ressalta-se que apenas foram considerados para esta investigação os MOOCs que no momento da pesquisa apresentavam os seus recursos ainda disponíveis. Portanto, todos os MOOCs encontrados que não possibilitavam o acesso ao seu conteúdo não foram incluídos na investigação.

A UNESCO possui um extenso trabalho de pesquisa e promoção da literacia midiática e informacional, sendo os MOOCs produzidos pela instituição um resultante desse trabalho. Neste tópico, será feita uma descrição analítica de dois dos 5 MOOCs de literacia midiática oferecidos no portal da UNESCO. O primeiro foi elaborado em 2015 em parceria com a Universidade de Athabasca (Canadá). Já o segundo MOOC é uma adaptação em português e se destina ao público brasileiro, feito em parceria com a UNICAMP.

A descrição analítica focaliza quatro dimensões (tecnológica, operacional, temática e pedagógica) de forma articulada. Todas as quatro dimensões se encontram, intercruzam-se, conectam-se e dialogam, entendendo que:

a) A dimensão tecnológica não aborda a questão apenas física da tecnologia. Assim, a dimensão tecnológica não se dá apenas pelos recursos materiais, mas pelo uso desses recursos e das suas técnicas por meio de ideias. Tratando-se do meio digital como aporte da dimensão tecnológica, desdobra-se o uso cultural desses recursos. Assim, o MOOC é disponibilizado enquanto um recurso educacional no meio digital, possível através da articulação das matérias e técnicas desenvolvidas e disponibilizadas que fazem parte do arcabouço cultural da sociedade. Nessa dimensão, identifica-se, por exemplo, qual a plataforma utilizada para portar o MOOC, ou se não é uma plataforma, mas sim uma conjunção de espaços digitais que, articulados, geram um ambiente virtual de aprendizagem (o caso de MOOC conectivista, que usa uma série de redes sociais articuladas como suporte).

b) A dimensão operacional é compreendida como a estrutura que viabiliza o curso em si, ou seja, o passo a passo de como funciona. Por exemplo, compreender a estrutura geral do curso e quais são os mecanismos de controle e de avaliação. Assim, nessa dimensão é possível traçar percepções sobre como o curso foi concebido e planejado pelos seus idealizadores.

c) A dimensão temática se refere ao contexto temático em que se centra o curso. Da temática central são extraídos subtemas que são abordados ao longo do curso, inclusive localizando a temática em uma determinada posição discursiva. Em relação à maneira como esses subtemas são abordados e articulados ao contexto temático central está a dimensão pedagógica.

d) A dimensão pedagógica é a maneira como a temática é abordada em termos de linguagem, estratégias para alcançar o cursista, bem como os recursos utilizados para isso: texto, vídeo, áudios, etc. Retomando aqui o item 4, as tipologias já determinam um modelo pedagógico, portanto, a dimensão pedagógica do MOOC se relaciona diretamente com a tipologia adotada. Ressalta-se que a dimensão pedagógica não se restringe ao tipo, abrange também as estratégias e recursos articulados na condução do curso, inclusive se essa condução é estruturada (modelo de transmissão), ou se parte da participação ativa dos alunos. 


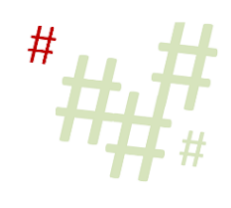

Todas as quatro dimensões fazem parte de um todo que é o próprio recurso educacional disponibilizado. Neste tópico, pretende-se definir e propor essas quatro dimensões como um suporte para a análise dos MOOCs. Portanto, a descrição analítica feita dos dois MOOCs selecionados compreende uma visão global, deixando espaço para que futuramente outras investigações se debrucem de forma pormenorizada em uma ou mais dimensões propostas aqui.

5.1 Literacia de Mídia e Informação e Diálogo Intercultural (MILID) - MOOC da Universidade de Athabasca (Canadá)

O MOOC em questão é uma parceria com a UNESCO, oferecido pela Universidade Aberta de Athabasca (Canadá) em língua inglesa. Entretanto, com a habilitação da tradução automática do navegador, é possível ter acesso à tradução da página do curso, bem como dos seus conteúdos em texto.

Em relação à operacionalidade, o curso é armazenado no sistema da própria universidade, disponível na plataforma Moodle, sendo possível o acesso de qualquer um através de login de convidado. O curso é gratuito, de acesso aberto, sem a necessidade de pagar nenhuma taxa de manutenção para cursá-lo. Foi disponibilizado em 2015, e sua última postagem foi registrada em 2019.

Como dinâmica de aprendizagem é sugerido que o cursista convide amigos, parentes e familiares para fazer o curso junto com ele, possibilitando a troca em pares de forma a fomentar o compartilhamento do aprendizado. Também, como dinâmica pedagógica é orientado a confecção de um "Diário de Experiência de Aprendizagem", podendo ser digital ou manuscrito. Nesse diário é sugerido que a extensão seja em torno de 200 palavras para cada unidade do curso, elaborado por meio de reflexão consciente sobre os aprendizados da unidade. Na página do MOOC é oferecido um glossário com os principais termos de domínio do curso para o auxílio de possíveis dúvidas.

Em relação à estrutura curricular, o curso é composto por 10 unidades com os seguintes tópicos: Unidade 1 - Alfabetização de mídia e informação (AMI): uma introdução; Unidade 2 - Alfabetização de mídia e informação e diálogo intercultural; Unidade 3 Alfabetização de mídia e informação: avaliando e usando informação e conteúdo de mídia; Unidade 4 - Alfabetização de mídia e informação: usando pesquisa e análise para produzir sua própria informação e conteúdo de mídia; Unidade 5 - Liberdade de expressão, liberdade de informação, liberdade de imprensa; Unidade 6 - Representações de Gênero na Mídia, Livros, na Internet e na História; Unidade 7 - Ética da mídia e da informação em relação às necessidades dos grandes negócios, política e desenvolvimento; Unidade 8 - Compreendendo e avaliando o mundo da publicidade; Unidade 9 - Os desafios e oportunidades da mídia, bibliotecas e novas tecnologias para jovens; Unidade 10 - Envolvendo-se com a mídia e usando novas tecnologias e informações para a ação social.

Os recursos pedagógicos utilizados são: fóruns, material para imprimir, recurso de vídeo e questionários. Esses recursos são apresentados por meio de hiperlinks que estão inseridos no conteúdo textual de cada unidade. Assim, cada unidade possui um tópico que é desdobrado por meio de conteúdo em texto e de vídeos complementares. Os textos são construídos com linguagem simples, possibilitando a compreensão por aqueles que não possuem altos níveis de escolarização (Figura 1). 


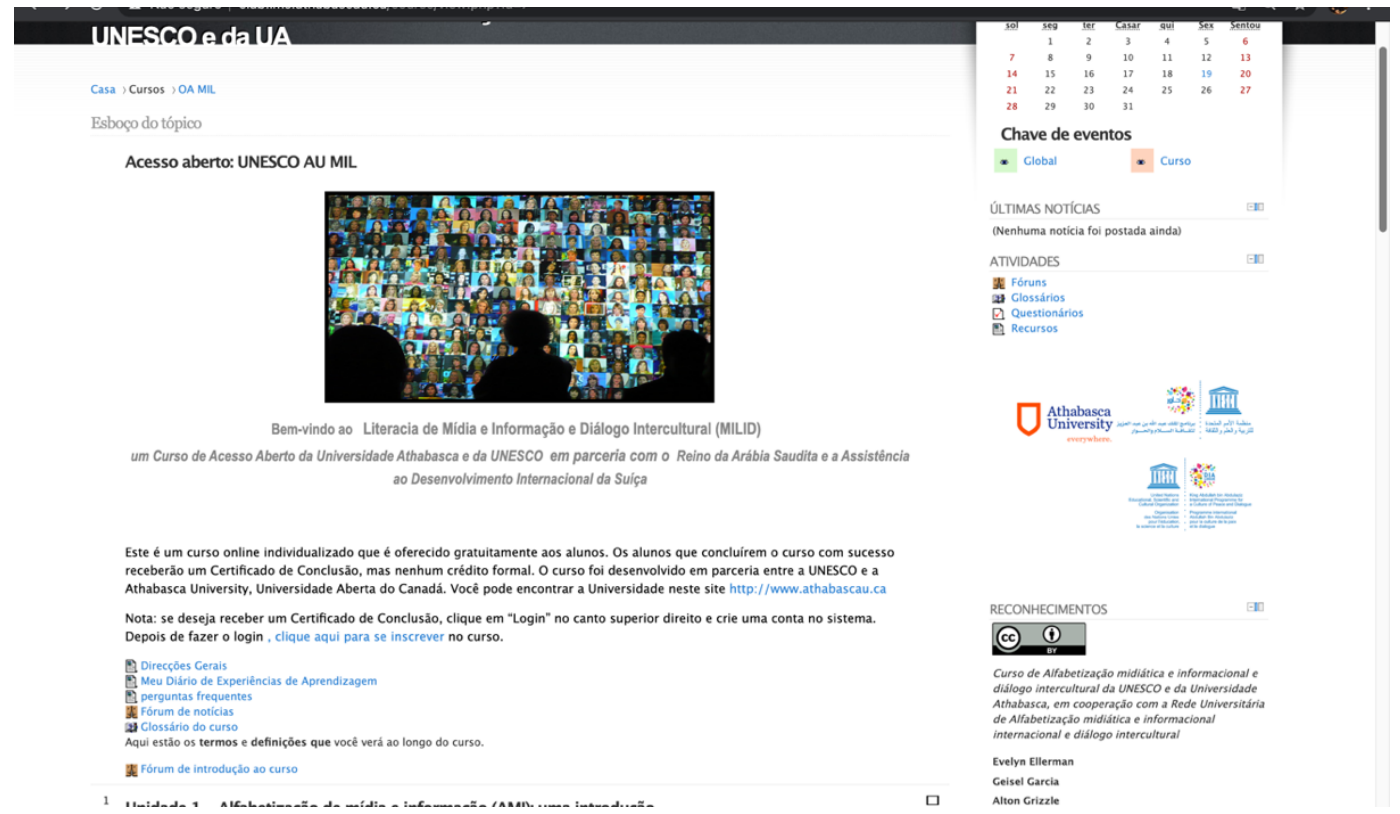

Fonte: Universidade de Athabasca (2015)

Ao fim de algumas das unidades, há uma atividade sugerida referente ao tópico abordado. Por exemplo, a Unidade 1 sugere que o cursista faça um blog para compartilhar suas reflexões acerca dos temas que serão abordados ao longo do curso. A partir da Unidade 2, o cursista precisará responder a um questionário no formato de quiz. A funcionalidade desse quiz é a avaliação do desempenho do cursista. Não sendo o desempenho um fator de retenção de uma unidade para outra, apenas um fator determinante para ter acesso ao certificado. O cursista que alcançar um percentual de aproveitamento de $65 \%$ poderá receber o certificado do curso.

5.2 Alfabetização Midiática, Informacional e Diálogo Intercultural - MOOC da Universidade Estadual de Campinas - UNICAMP (Brasil)

É um MOOC traduzido e adaptado do curso em inglês abordado no tópico anterior. Diferente do curso da Universidade de Athabasca, encontra-se disponível na plataforma da Coursera. Essa plataforma apresenta padronização em relação à estruturação de seus cursos. Assim, possui um guia na página inicial do ambiente do curso mostrando a evolução do cursista em relação às atividades semanais. $O$ curso é inteiramente gratuito, apenas é cobrada uma taxa para aqueles que solicitarem o certificado.

Em relação à estrutura curricular, a cada semana é abordado um tópico, distribuídos em 10 semanas: Semana 1 - Introdução: Alfabetização midiática e informacional; Semana 2 Alfabetização em Mídia, Informação e Diálogo Intercultural; Semana 3 - Alfabetização midiática e informacional: avaliando e usando informações e conteúdo midiático; Semana 4 Alfabetização midiática e informacional: usando pesquisa e análise para produzir sua própria informação e conteúdo de mídia; Semana 5 - Liberdade de expressão, liberdade de informação, liberdade de imprensa; Semana 6 - Representação de Gênero na mídia, nos livros, na internet e na História; Semana 7 - Ética da mídia e da informação em relação às necessidades dos grandes negócios, política e desenvolvimento; Semana 8 - Entendendo e 
avaliando o mundo da publicidade; Semana 9 - Desafios da internet e Oportunidade para crianças e jovens; Semana 10 - Envolvendo-se com mídia e usando nova tecnologia e informação para ação social.

Os recursos pedagógicos utilizados pelo curso são marcados principalmente pelo layout do próprio Coursera, que os localiza em relação ao tipo e ao tempo sugerido (Figura 2).

Figura 2 - Ambiente MOOC UNICAMP\UNESCO

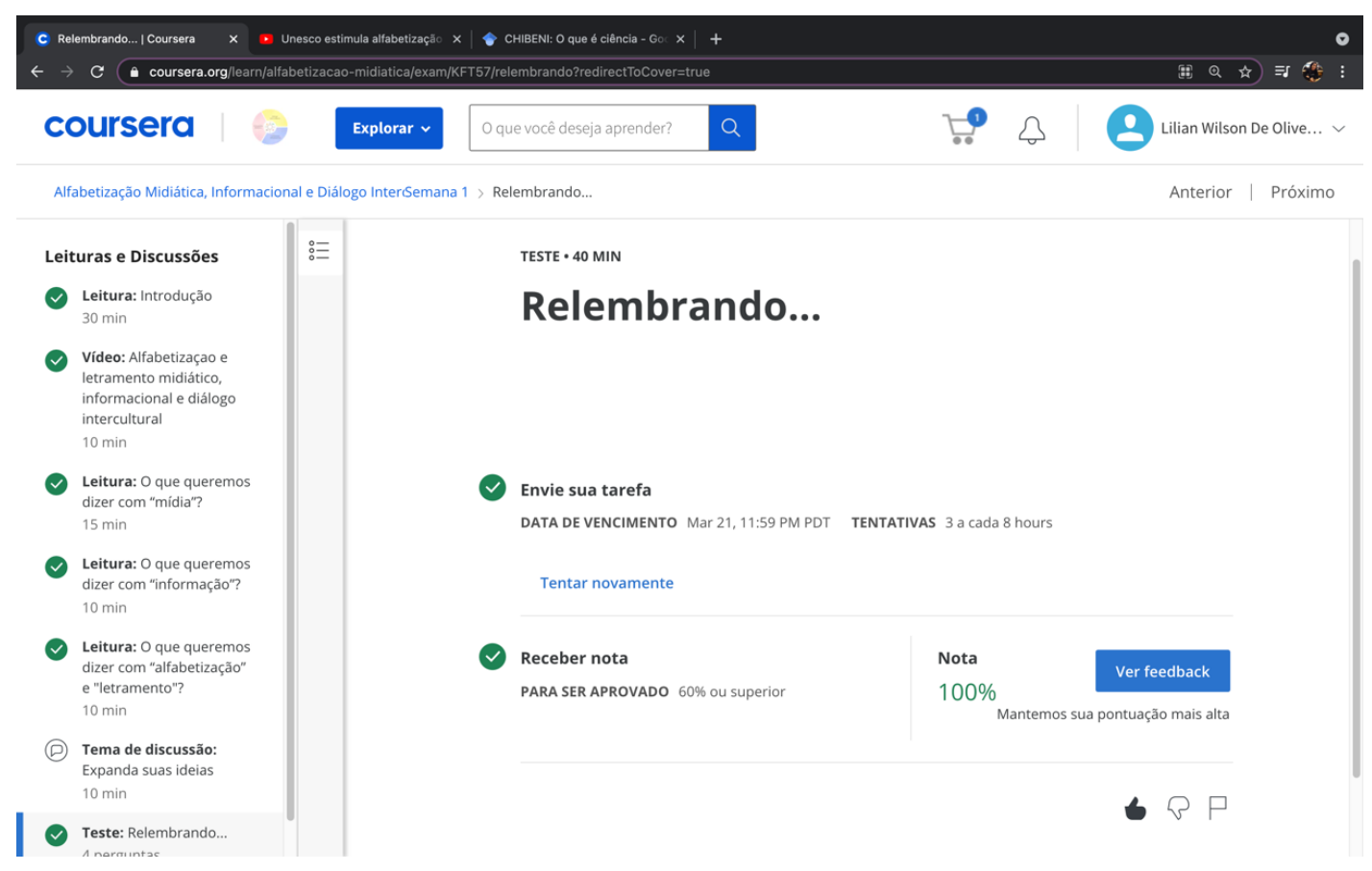

Fonte: Coursera (2021)

O conteúdo em texto possui linguagem simples, tornando-se acessível ao público em geral. Observa-se a presença de hyperlinks em palavras-chave que direcionam para diversos conteúdos e fontes. Cada semana, o cursista tem a sua disponibilidade as leituras e os vídeos selecionados. Como recurso complementar, o cursista pode acessar o fórum e enviar um comentário sobre o tema semanal, sendo uma atividade opcional. As atividades são estruturadas de forma linear e ao, findar uma, habilita-se a seguinte, podendo o cursista retornar ao conteúdo das seções anteriores. Ao fim de cada tópico semanal, deve-se responder a um questionário. Para avançar à próxima temática, deve-se ter um percentual de acerto de $65 \%$, portanto, o questionário é um instrumento avaliativo e que promove retenção.

Observa-se em alguns dos questionários presentes ao final de cada sessão que a elaboração não facilitou a compreensão em relação à dinâmica, pois não há um enunciado que oriente como efetuar elaboração das respostas. Assim, não há nenhuma explicação em tela que sinalize, por exemplo, para marcar todas as opções corretas, e não apenas uma. Essa falta de orientação pode desestimular o aluno, que necessita fazer mais de uma vez o questionário até compreender que deve marcar em cada questão todas as alternativas corretas sobre o assunto. 


\subsection{Aproximações e distanciamentos dos MOOCs apresentados}

Em relação à tecnologia, os cursos se diferem por usar diferentes tipos de plataformas, apesar de ambas serem em sistema LMS (Learning Management System, em português Sistema de Gestão de Aprendizagem). O MOOC da Universidade de Athabasca encontra- se hospedado na plataforma Moodle, enquanto o MOOC da UNICAMP está hospedado na plataforma da Coursera. Dessa forma, há diferença na operacionalidade dos MOOC. Enquanto o Moodle oferece ao instrutor e ao cursista uma mentoria mais próxima, a plataforma do Coursera não possibilita a interação dos instrutores com os cursistas.

O Moodle também é uma sigla (Modular Object-Oriented Dynamic Learning Environment, em português Ambiente de Aprendizado Dinâmico Modular Orientado a Objetos) e antecede o próprio MOOC, disponibilizado em 2002. O Moodle é, portanto, uma plataforma que pode hospedar um MOOC como outros tipos de cursos e-learning. Já o Coursera é uma empresa que surgiu em 2012 para vender o serviço de hospedagem de cursos MOOC em sua plataforma, por meio do convênio com renomadas universidades ao redor do mundo, como é o caso da UNICAMP. Ressalta-se que muitos pesquisadores apontam o caráter mercadológico desse tipo de plataforma, que funciona como vitrine de promoção de algumas universidades em detrimento de outras. Knox (2016) aponta para esse fenômeno de MOOCs em plataformas como uma nova colonização do saber por meio da padronização da educação global.

Em relação à temática e à ordem em que os temas são abordados, os dois MOOC não apresentam distanciamentos. Inclusive, seguem a mesma sequência temática e dividem a temática central na mesma quantidade de sessões. Essas temáticas são encontradas nos documentos norteadores da UNESCO. Ainda sobre a dimensão temática, o MOOC da UNICAMP apresenta no conteúdo da sua introdução uma atualização referente ao contexto da desordem da informação, principalmente por ser um curso mais recente. Assim, na introdução, os desenvolvedores citam a importância da literacia midiática e informacional para enfrentar o contexto de difusão de notícias falsas.

O MOOC da UNICAMP demarca que a compreensão da literacia midiática e informacional do diálogo cultural auxilia a compreender o processo de polarização política atual do Brasil no momento que se fomenta a participação dialógica. Embora essa atualização do conteúdo faça com que o MOOC da UNICAMP ganhe um aspecto de recurso de enfrentamento aos processos da desordem da informação, não se revela em uma introdução de tópicos específicos para essa finalidade.

Em relação à dimensão pedagógica, ambos os cursos são da tipologia xMOOC. Embora apresentem estratégias de conectividade (por meio de hiperlinks), a ótica pedagógica desse tipo de MOOC é centrada na forma tradicional de transmissão de conteúdos, o aprendizado autorregulado que não requer interação, nem estimula a interação entre os participantes do curso. Portanto, a tipologia xMOOC limita em certo ponto a abordagem das habilidades da literacia midiática e informacional, pois não fomenta a interação entre os cursistas e tutores. Há um estímulo de criar interação fora do curso (quando sugere a construção de blogs ou postagem em rede social), contudo, são atividades sugeridas como extracurriculares.

Por conseguinte, as habilidades de acessar, analisar e avaliar as mídias e informações são estimuladas a partir do conteúdo apresentado nos tópicos com os recursos de texto e 
vídeo. Mas as habilidades de criar e fazer uso ativo das mídias e das informações não são contempladas na ótica da transmissão de conteúdo típica do xMOOC. Nesse sentido, seriam necessário recursos que estimulassem a inversão do polo de transmissão de conhecimento, gerando maior engajamento e interação dos cursistas para que de fato a literacia midiática e informacional fosse relacionada às práticas de cidadania ativa.

Após o término das sessões há a presença de uma avaliação com o objetivo de verificar o conteúdo apreendido pelo aluno, estrutura típica de um xMOOC. No curso da UNICAMP, da plataforma Coursera, a avaliação de cada módulo é componente integrante de todas as sessões, utilizado, inclusive, como instrumento de retenção. Já no curso da Universidade de Athabasca não são todas as sessões que apresentam um questionário final, não sendo um mecanismo de retenção.

Sobre a dimensão pedagógica, o MOOC da Universidade de Athabasca apresenta uma preocupação marcada em demonstrar as fontes acadêmicas em relação, principalmente, aos conceitos utilizados de forma demarcada. Já o curso da UNICAMP utiliza hiperlink em algumas palavras-chave que se alternam em uma definição demarcada, quando direcionada para o site da Wikipédia, por exemplo, ou de forma mais plural quando direciona para uma lista de artigos presente no mecanismo de busca Google Acadêmico. Em ambos os cursos, há o estímulo para que o cursista trabalhe a sua própria definição dos conceitos-chave da unidade, entretanto, não desenvolvem pedagogicamente estratégias concisas que o instrumentalize a criar definições.

\section{Considerações Finais}

Os estudos de literacia midiática e informacional que remontam ao início dos anos 2000 já apontavam a necessidade de implantar medidas para educação midiática dado o cenário evolutivo das mídias. Embora haja a presença de inúmeras pesquisas que apontam a necessidade de ações mais concretas por parte dos órgãos governamentais, no Brasil ainda não há uma diretiva oficial específica - apesar da BNCC fazer menção à questão e fomentar a inclusão da temática na formação de professores.

Ao verificar a ocorrência dos MOOC que promovem a literacia midiática e informacional, compreende-se que essa modalidade de ensino é propícia para abordagem do conjunto de habilidades da competência em questão. Por outro lado, a ocorrência dos MOOC promotores de literacia midiática e informacional sugere a necessidade de abordar a temática não só no campo da educação formal, mas também na perspectiva do aprendizado ao longo da vida. Essa forma de abordagem reforça não só o caráter de atualização da temática em relação às novas tecnologias que surgem, mas também como uma medida de conferir acesso aos que estão há muito tempo fora dos bancos escolares e aos cidadãos de forma geral que buscam formação de maneira contínua.

Como resultado foi identificado que todos os MOOC catalogados são da tipologia xMOOC, que é focada na transmissão do conteúdo de um para muitos. Assim, não são abordadas pelos cursos analisados as habilidades da literacia midiática e informacional que requerem a inversão do polo de construção de conhecimento (participação e uso ativo das mídias), apesar de serem estimuladas por meio de produção fora do ambiente do curso. 
Ainda é recente a identificação da desordem de informação em rede, sendo, desse modo, um desafio traçar estratégias para o seu enfrentamento. Como recurso para países que não possuem políticas públicas específicas de Educação Midiática, como é o caso do Brasil, a presença de MOOC que aborde a temática da literacia midiática e informacional, sobretudo na língua nativa, funciona como um recurso potencial para o empoderamento da população que utiliza diversos recursos online, fazendo com que se sinta mais instrumentalizada para as sociabilidades que se desdobram com as/nas mídias.

O artigo em questão focalizou o MOOC de literacia midiática e informacional a fim de identificar a sua oferta e compreender a sua dinâmica, para relacioná-la à abordagem da literacia midiática e informacional no contexto da desordem da informação. Ressalta-se aqui a importância de reconhecer os limites do estudo e da própria área da Educação em relação aos fenômenos da desordem da informação, visto que tal fenômeno mobiliza assuntos de diversas áreas (saúde, ecologia, política, etc). Entende-se que, além do fomento à pesquisa, é necessário um esforço da sociedade em geral, envolvendo diversas instituições (governamentais e não governamentais) em diferentes âmbitos (educacional, judicial, político, comercial etc.) para fortalecer o campo de estudos da educação midiática, especialmente, sobre o tema do combate às notícias falsas e da cidadania nas redes sociais.

\section{Referências}

ALDAHMANI, Salem et al. A Review Paper on MOOCs Development Stages, Types, and Opportunities and Challenges. A Multifaceted Review Journal in the field of Pharmacy, India, v. 11, n.12, p. 172-179, 2020. Disponível em: https://www.sysrevpharm.org/fulltext/196-1599893674.pdf. Acesso em: 10 fev. 2020

APPLE, Michel W. A educação pode mudar a sociedade? Ed. Digital. Petrópolis, RJ: Vozes, 2017.

ATHABASCA UNIVERSITY. Media and Information Literacy and Intercultural Dialogue (MILID), 2015. Página Inicial. Disponível em: http://elab.lms.athabascau.ca/ . Acesso em: 02 fev. 2021.

BORGES, Gabriela; SIGILIANO, Daiana; GUIDA, Vinícius. Competência midiática e formação para a cidadania: oficinas de criação do Observatório da Qualidade no Audiovisual. Tríade: Comunicação, Cultura e Mídia, São Paulo, v.9, n.20, p. 24-50, 2021. Disponível em: http://periodicos.uniso.br/ojs/index.php/triade/article/view/4658. Acesso em: 10 maio 2021.

BULGER, Monica; DAVISON, Patrick. The Promises, Challenges, and Futures of Media Literacy. Journal of Media Literacy Education, Estados Unidos, v. 10, n. 1, p.1 - 21, 2018. Disponível em: https://digitalcommons.uri.edu/jmle/vol10/iss1/1/. Acesso em: 10 fev. 2020.

CARMO, Hermano; CARMO, Teresa Maia. Valor dos Massive Open Online Course (MOOC) na educação para a cidadania. Inclusão Social, Brasil, v.10, n.1, p. 33-48, 2016. Disponível em: https://periodicos.ufpb.br/index.php/pbcib/article/view/42995. Acesso em: 10 fev. 2020 
COURSERA. Alfabetização e letramento midiático, informacional e diálogo intercultural, 2021. Página Inicial. Disponível em: https://www.coursera.org/lecture/alfabetizacao-midiatica/alfabetizacao-e-letramento-midiatico -informacional-e-dialogo-intercultural-Y1gSV. Acesso em: 02 fev. 2021.

DEVAUX et al. Study on media literacy and online empowerment issues raised by algorithm-driven media services. Luxembourg: Publications Office of the European Union, 2019

GREENE, Jeffrey; OSWALD, Christopher; POMERANTZ, Jeffrey. Predictors of retention and achievement in a massive open online course. American Educational Research Journal, Estados Unidos, v. 52, n.5, p. 925-955, 2015. Disponível em: https://journals.sagepub.com/doi/10.3102/0002831215584621. Acesso em: 20 jul. 2020.

HOBBS, Renee. Digital and media literacy: A plan of action. Edição Digital. Estados Unidos: Aspen Institute and Knight Foundation, 2010. Disponível em: https://assets.aspeninstitute.org/content/uploads/2010/11/Digital_and_Media_Literacy.pdf. Acesso em: 15 nov. 2019.

IRETON, Cherilyn; POSENTTI, Julie. Introduction in Journalism, 'Fake News e Disinformation: Handbook for Journalism Education and Training. Edição Digital. França: UNESCO, 2018. Disponível em: https://en.unesco.org/fightfakenews. Acesso em: 15 nov. 2019.

KNOX, Jeremy. Posthumanism and the massive open online course: contaminating the subject of global education. New York: Routledge, 2016.

LOPES, Paula. Mentiras, Pegadas e algoritmos: Da necessidade de uma educação para os media. In: LOPES, P.; REIS, B. Comunicação digital: Media, Práticas e Consumos. Edição Digital. Lisboa, Portugal: NIP-C@M, 2019. Disponível em: http://hdl.handle.net/11144/3969. Acesso em: 12 jun. 2020.

MISSOPOULOS, Fotios; ARGYROPOULOU, Maria; TZAVARA, Dionisia. Exploring the factors affecting student academic performance in online programs: A literature review. In Anshuman, Khare; Hurst, Deborah. On the line: Business Education in The Digital Age. Alemanha:Springer, 2018. Disponível em:

https://link.springer.com/chapter/10.1007\%2F978-3-319-62776-2_18. Acesso em: 17 nov. 2019

NEWMAN, Nic et al. Reuters Institute Digital News Report 2019. Oxford, Reino Unido: Reuters Institute, 2019. Disponível em: http://www.digitalnewsreport.org/survey/2019/. Acesso em: 25 mai. 2020.

NEWMAN, Nic et al. Reuters Institute Digital News Report 2020. Oxford, Reino Unido: Reuters Institute, 2020. Disponível em: http://www.digitalnewsreport.org/survey/2020/. Acesso em: 25 jan. 2021.

RIBEIRO, Luis; CATAPAN, Araci. Plataformas MOOC e Redes de Cooperação na EAD. EmRede Revista de Educação a Distância, v. 5, n.1, p. 45-62, 2018. Disponível em: https://www.aunirede.org.br/revista/index.php/emrede/article/view/297. Acesso em: 15 nov. 2019. 
STRACKE, Christian et al. Are MOOCs Open Educational Resources? A literature review on history, definitions and typologies of OER and MOOCs. Open Praxis, v. 1, n. 4, p. 331-34, 2019. Disponível em: https://doi.org/10.5944/openpraxis.11.4.1010. Acesso em: 25 nov. 2020.

STRACKE, Christian. Como a Educação Aberta pode melhorar a qualidade de aprendizagem e produzir impacto em alunos, organizações e na sociedade? In Duran, Maria; Amiel, Tel, Costa, Celso. Utopias e distopias da tecnologia na educação à distância e aberta. Niterói, Rio de Janeiro: CEAD \UFF, 2018

UNESCO. Global Media and Information Literacy Assessment Framework: Country Readiness and Competencies. França: UNESCO, 2013. Disponível em: https://unesdoc.unesco.org/ark:/48223/pf0000224655. Acesso em: 27 jun. 2020.

UNESCO. Seoul Declaration on Media and Information Literacy for Everyone and by Everyone: A Defence against Disinfodemics. Coréia do Sul: UNESCO, 2020. Disponível em: https://en.unesco.org/sites/default/files/seoul_declaration_mil_disinfodemic_en.pdf. Acesso em: 27 jan. 2021.

WAKS, Leonard. The evolution and Evaluation of Massive Open Online Courses: MOOCs in Motion. Edição digital. Estados Unidos: Palgrave Macmillan, 2016.

WARDLE, Claire; DERAKHSHAN, Hossein. Information disorder: Toward an interdisciplinary framework for research and policy making. Strasbourg, França: Council of Europe, 2017. Disponível em:

$\mathrm{https} / / / \mathrm{rm}$.coe.int/information-disorder-toward-an-interdisciplinary-framework-for-researc/16 8076277c. Acesso em: 15 nov. 2019.

YOUSEF, Ahmed at el. MOOCs a review of the state-of the-art. CSEDU - 6th International Conference on Computer Supported Education, v.6, n.3, p. 9-21, 2014. Disponível em: http://www.csedu.org/?y=2014. Acesso em: 20 dez. 2019.

ZAROCOSTAS, John. How to fight an infodemic. The Lancet, v.395, n.10225, p.676, 2020. Disponível em: https://doi.org/10.1016/S0140-6736(20)30461-X. Acesso em: 17 jul. 2020.

Recebido em março de 2021.

Aprovado em maio de 2021. 